\title{
Adaptive Locomotion for Crossing a Moving Obstacle
}

\author{
Jean Jose da Silva, Fabio Augusto Barbieri, \\ and Lilian Teresa Bucken Gobbi
}

\begin{abstract}
Crossing moving obstacles requires different space-time adjustments compared with stationary obstacles. Our aim was to investigate gait spatial and temporal parameters in the approach and crossing phases of a moving obstacle. We hypothesized that obstacle speed affects gait parameters, which allow us to distinguish locomotor strategies. Ten young adults walked and stepped over an obstacle that crossed their way perpendicularly, under three obstacle conditions: control - stationary obstacle, slow $(1.07 \mathrm{~m} / \mathrm{s})$ and fast speed $(1.71 \mathrm{~m} / \mathrm{s})$ moving obstacles. Gait parameters were different between obstacle conditions, especially on the slow speed. In the fast condition, the participants adopted predictive strategies during the approach and crossing phases. In the slow condition, they used an anticipatory strategy in both phases. We conclude that obstacle speed affects the locomotor behavior and strategies were distinct in the obstacle avoidance phases.
\end{abstract}

Keywords: control mode, moving obstacle, locomotor strategies.

Efficient locomotion includes a basic locomotor rhythm, dynamic body balance control, and adaptation to environmental requirements and to task goals (Patla, 1991; Shumway-Cook \& Woollacott, 1995). The presence of an obstacle in the locomotion path requires more attention (Lindenberger, Marsiske \& Baltes, 2000) and makes it difficult to maintain the locomotion features. For this reason, adaptive locomotion requires the harmonic combination of the sensory and the motor systems (Patla, Prentice \& Gobbi, 1996). Perceiving the spatial layout is such a primary task of the visual system that people intuitively assume that relative visual localization is performed very efficiently and without error (Watanabe, 2004).

Sensorimotor combinations occur in three controlling levels. The individual must: 1) formulate a plan of action, which involves perception and cognition; 2) assess the environmental layout and plan a detailed travel path; 3) regulate speed and direction as necessary to stay on the path (Loomis \& Beall, 1998). Adjustments in locomotion result from choices known as adaptive strategies, which are behavioral changes made to attain the final objective (Troisi, 2005) and to ensure the successful motor action. During walking, for example, we need to modulate, increasing or decreasing, our velocity when an object or animal crosses in front of us. This modulation assures the action success, without collision or risk of falling.

The authors are with UNESP—Physical Education, Rio Claro, São Paulo, Brazil. 
Both the selection of adaptive strategies and the modulation of locomotor patterns are cognitive factors related to adaptive locomotion (Patla, Cinelli \& Greig, 2006). Theoretically, the achievement of dynamic stability during locomotion occurs through reactive, predictive and anticipatory strategies (Patla, 2003). Predictive and anticipatory strategies are under proactive control, which implies that both use sensory information for detection of potential perturbations related to either environment features or ongoing movements. In particular, an anticipatory strategy involves the use of sensory information, primarily by vision, to identify potential perturbations on the travel path. A predictive strategy seems to rely upon past experience and they are related to the prediction of motor perturbations elicited by either isolated or concurrent voluntary movements. Experience guides proactive control of dynamic balance during locomotion. Reactive strategies occur in response to an unexpected perturbation by mono- and poli-synaptic reflexes, when dynamic stability must be restored. Related to our purposes, proactive control mechanism are involved during both the approaching and the crossing phases of a moving obstacle. In addition, reactive strategies only are necessary if the participants lost the dynamic balance control by tripping or by moving their center of mass out of the base of support.

When crossing an obstacle, individuals modulate the effector system according to obstacle characteristics (Mohagheghi, Moraes \& Patla, 2004; Siu et al., 2008). Young adults modulate the take off distance, toe clearance, and gait speed according to the obstacle features (Patla, Prentice \& Gobbi, 1996; Bradshaw \& Sparrow, 2001; Krell \& Patla, 2002; Mohagheghi, Moraes \& Patla, 2004). These variables indicate the strategies used to cross stationary obstacles, for example, a fragile obstacle elicited a motor modulation revealed by an increased toe clearance and a reduction of both the take off distance and the gait speed (Patla et al., 1996). Moving obstacles probably require different space-time adjustments to couple with environment changes (Patla, Cinelli \& Greig, 2006). Patla and colleagues (2006) reported two experiments with moving/changing obstacle in the travel path (headon collision moving toward the subject and steering through gaps in the sliding doors). However, it is unknown the required adaptive strategies when the obstacle movement is perpendicular to the individuals' movement.

The study of adaptive strategies in crossing moving obstacles is important, since individuals interact dynamically with the environment by space-time adjustments and sensory-motor combination of movement to avoid falls and injuries. On crossing a moving obstacle, individuals attempt to simplify the task to attain the obstacle direction (Cinelli, Patla \& Allard, 2008). This task requires more sensory attention and results in decreased motor performance according to obstacle position (Gérin-Lajoie, Richards \& McFadyen, 2006). However, the reported studies did not manipulate obstacle speed that also varies dynamically.

The objective of this experiment was to analyze the space-time parameters of locomotor behavior in crossing a moving obstacle and to identify the adaptive strategies used in this task. Specifically, the aim was to compare the locomotor parameters in obstacle crossing in two conditions: slow and fast obstacle speed in relation to the locomotor behavior in crossing a stationary obstacle. The study hypothesis is that obstacle speed affects gait parameters, showing proactive strategies, such as the reduction of step length and duration in the approach phase and the take off and landing distances in the crossing phase, among others. As the task 
becomes more complex with increased obstacle speed, the amount of locomotor changes will increase. It is also expected that the space-time movement adjustments in different speed conditions will be distinct, but similarly controlled by the proactive mechanisms.

\section{Materials and Methods}

The study participants were five male and five female young adults (age $=22.8$ \pm 1.8 years, mass $=64.3 \pm 10.1 \mathrm{~kg}$, height $=1.70 \pm 6.8 \mathrm{~m}$ ), with either normal or corrected-to-normal vision and without any known neurological or musculoskeletal system impairment or sensory-motor disorders that might make accomplishing the task difficult. All participants were preferred right-foot. The individuals gave their free informed consent of participation in the study, after the approval by the local Research Ethics Committee (Protocol\# 004387/2003).

Participants' instructions were to walk an $8 \mathrm{~m}$ long $\times 0.5 \mathrm{~m}$ wide rubberized mat walkway and cross the obstacle with the right leg leading exactly when the obstacle crossed the walkway. The walkway width limited the crossing area. Three obstacle conditions were presented: control (stationary obstacle), obstacle crossing the path perpendicularly to the participant's direction in slow speed $(1.07 \mathrm{~m} / \mathrm{s})$ and fast speed $(1.71 \mathrm{~m} / \mathrm{s})$. The speeds were determined as a function of the average adult gait speed $(1.33 \mathrm{~m} / \mathrm{s})$, which correspond to a $20 \mathrm{rpm}$ in the frequency inverter. To increase the speed control the slow and fast speeds were established as 15 and 25 rpm, respectively, and these speed also correspond to the lower and upper limits of preferred adult gait speed (Winter, 1991).

The participants crossed a $0.5 \mathrm{~cm}$ wide $\times 50 \mathrm{~cm}$ long wood obstacle. The obstacle height was customized to each participant. The knee height of each participant (obstacle height average $=49 \pm 3.5 \mathrm{~cm}$ ) was established as obstacle height since it is the threshold for the adaptive locomotor behavior in young adults (Patla, 1997). The obstacle was fixed to a carriage moving on $6 \mathrm{~m}$ long rails. The obstacle driving mechanism (carriage, rails, and control box) was made of steel and especially built for this purpose (Figure 1a). The obstacle carriage was $5.5 \mathrm{~cm}$ high and $50 \mathrm{~cm}$ long. It had a touch-sensitive unlatching mechanism designed for the participants' maximum safety in performing the task. The control box commanded an engine (WEG, model 71, $0.33 \mathrm{hp}$, three-phase, $1.6 \mathrm{~A}, 60 \mathrm{~Hz}, 220 \mathrm{~V}$, 1720 RPM) through a frequency inverter (TOSHIBA, model VF-SX, $220 \mathrm{~V}, 0.75$ $\mathrm{kW}$ ); the engine rotation frequency was shown on the panel. The inverter switch controlled the obstacle movement direction.

A marker placed at $3.5 \mathrm{~m}$ from the rail on the walkway indicated the point at which the obstacle-driving engine started. The obstacle ran $(\sim 3 \mathrm{~m})$ from the departure point beside the path to the middle of the walkway (Figure 1b). A board $(80 \mathrm{~cm}$ high $\times 1 \mathrm{~m}$ long) placed at the beginning of the obstacle path prevented the subject perception of the obstacle acceleration. The obstacle-driving engine started during the participant trajectory, reducing the possibilities for anticipation. The participants performed three trials in each condition for familiarization purposes. During practice trials, the departure point was defined to guarantee the right limb as leading limb according to methodological constraints (camcorders recorded the individual right sagital plane). Fifteen trials in five-attempt blocks were recorded 


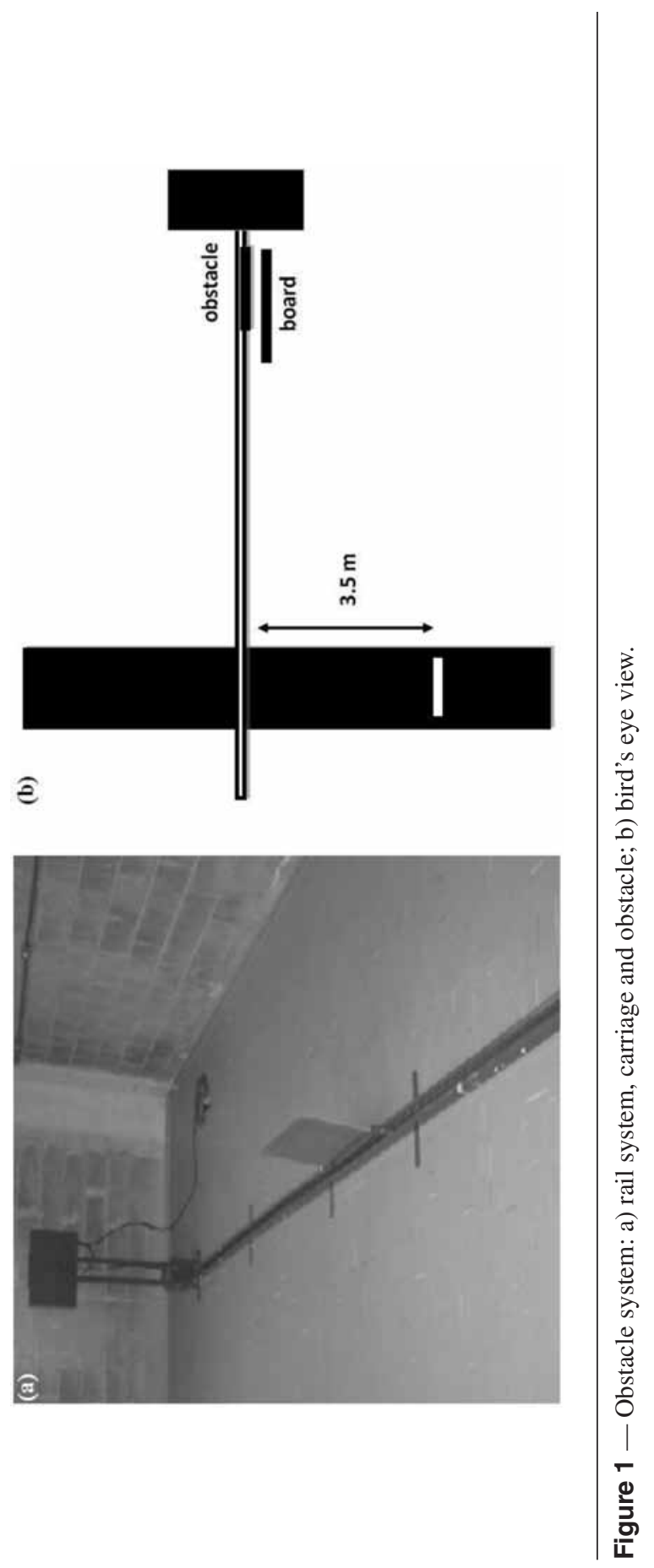


for each participant in each condition. The blocks were presented to the participants at random. Out of the 150 trials made by all the participants, $20 \%$ were repeated at the end of each block of trials. Among them, $12 \%$ were with the moving obstacle, $55.5 \%$ of which were in slow obstacle speed and $44.5 \%$ in fast obstacle speed. For stationary obstacle, $8 \%$ were repeated. Trial repetition was required mostly due to methodological failures than to task performance errors.

Passive markers were set at the participants' anatomical points: fifth toe and lateral side of right and left calcaneus. A marker was also set at the obstacle top right side. The participants were recorded with two digital camcorders (JVC-model GR-DVL 9800) with shutter speed of $1 / 250$ and $60-\mathrm{Hz}$ field rate. The camcorders were placed at $90^{\circ}$ to each other on the right sagittal plane to the individual's movement. A cube frame $(1.5 \times 1 \times 4 \mathrm{~m})$ calibrated the measurement area. The $3 \mathrm{D}$ coordinates were expressed as right-handed and the $\mathrm{z}$ axis was vertical (pointing upward), the y axis was horizontal along the walking direction (anterior-posterior) and the $\mathrm{x}$ axis was the vector product of $\mathrm{y}$ and $\mathrm{z}$ (medial-lateral). DVIDEOW software (Figueroa, Leite \& Barros, 2003) was used to analyze the images. The DLT-Direct Linear Transformation method (Abdel-Aziz \& Karara, 1971) was implemented in this software and used to obtain the 3D coordinates of each marker. Data filtering used the fourth-order Butterworth digital filter at cutoff frequency of $5 \mathrm{~Hz}$.

To evaluate the experimental errors, an accuracy test was performed. Through the recording movements of a rigid rod, we calculated the accuracy. Two 15-mm diameter landmarks were placed at each end of a rigid rod at a known distance apart (direct measurement). Accuracy was calculated by normalizing the actual dimension by the digital dimension. It was obtained an error of $16.72 \mathrm{~mm}$.

The study dependent variables (Table 1) were analyzed in the two steps before (last stride), during, and after crossing the obstacle. Except for the horizontal linear distance to the obstacle, gait speed, and linear acceleration, the variables were statistically treated by trial with variance analysis (one-way ANOVA) with repeated measurements for the obstacle conditions. Tukey's test was performed for planned comparisons. The step length in N-2 and N-1 was analyzed intracondition by paired $t$ test with SPSS10.0@ at significance level of $\alpha<.05$.

The linear gait speed at each moment was examined considering the horizontal components ( $\mathrm{x}$ and $\mathrm{y}$ axes) of the right calcaneus marker. Then, the first derivative of linear regression lines fitted to their nonfiltered displacements was calculated. The vertical component ( $\mathrm{z}$ axis) was calculated as the first derivative of a quadratic regression line with its second derivative set equal to $-9.81 \mathrm{~m} / \mathrm{s}$ fitted to its nonfiltered displacement in the available airborne frames. The linear gait acceleration was calculated through the derivative of the linear speed as a function of time. Gait speed, acceleration, and linear distance were analyzed from the median and respective confidence intervals of each time instant. Confidence intervals were used to verify the differences between the velocity conditions (MacGill, Tukey \& Larsen, 1978). If those confidence intervals overlapped, the differences were significant. Matlab 6.5 software was used in these analyses. 


\section{Table 1 List of Definitions of the Dependent Variables.}

\begin{tabular}{|c|c|}
\hline Dependent Variable & Definition \\
\hline $\mathrm{N}-2$ & \multirow{2}{*}{$\begin{array}{l}\text { Horizontal distance (y axis) between the right and left } \\
\text { calcaneus in last but one (N-2) and last steps (N-1) before } \\
\text { the obstacle approach. }\end{array}$} \\
\hline $\mathrm{N}-1$ & \\
\hline $\begin{array}{l}\text { horizontal linear } \\
\text { distance to the } \\
\text { obstacle }\end{array}$ & $\begin{array}{l}\text { Horizontal distance (y axis) from the right calcaneus (lead } \\
\text { limb) to the obstacle at each moment of time. The cycle } \\
\text { analyzed was } \mathrm{N}-2(0 \% \text { of the cycle) until the moment of right } \\
\text { calcaneus was above the obstacle }(100 \% \text { of the cycle). The } \\
\text { moment of right calcaneus was above the obstacle was defined } \\
\text { as zero meters. }\end{array}$ \\
\hline take-off distance & $\begin{array}{l}\text { Horizontal distance (y axis) from the fifth right metatarsal joint } \\
\text { (lead limb) in the toe-off to the obstacle before crossing the } \\
\text { obstacle. }\end{array}$ \\
\hline landing distance & $\begin{array}{l}\text { Horizontal distance (y axis) from the fifth right metatarsal joint } \\
\text { (lead limb) in the heel contact to the obstacle after crossing the } \\
\text { obstacle. }\end{array}$ \\
\hline toe clearance & $\begin{array}{l}\text { Vertical distance ( } \mathrm{z} \text { axis) from the fifth right metatarsal joint } \\
\text { (lead limb) to the obstacle at the time when the foot was above } \\
\text { it. }\end{array}$ \\
\hline absolute error & $\begin{array}{l}\text { Lateral distance (x axis) from the fifth right metatarsal joint } \\
\text { (lead limb) to the midpoint of the obstacle at the time of } \\
\text { crossing. }\end{array}$ \\
\hline $\mathrm{N}-2$ duration & \multirow{2}{*}{$\begin{array}{l}\text { Duration of contact between the right and left calcaneus in N-2 } \\
\text { and N-1. }\end{array}$} \\
\hline N-1 duration & \\
\hline crossing duration & $\begin{array}{l}\text { Duration of right foot toe-off (lead limb) before crossing } \\
\text { the obstacle until its next hell contact. }\end{array}$ \\
\hline cadence & Number of strides per second before crossing the obstacle. \\
\hline average gait speed & Average gait speed from N-2 to obstacle. \\
\hline linear gait speed & $\begin{array}{l}\text { Linear gait speed during the gait cycle before crossing } \\
\text { the obstacle. }\end{array}$ \\
\hline linear gait acceleration & $\begin{array}{l}\text { Linear gait acceleration during the gait cycle before crossing } \\
\text { the obstacle. }\end{array}$ \\
\hline
\end{tabular}

\section{Results}

Cadence was significantly higher at fast $(2.06 \pm 0.28$ stride/s $)$ speed than in the other conditions and in the control $(1.88 \pm 0.22$ stride/s) condition relative to the slow $(1.55 \pm 0.29$ stride/s $)$ speed condition $\left(\mathrm{F}_{3,38}=39.91, p<.001\right)$. ANOVA showed significantly bigger $\mathrm{N}-2$ and $\mathrm{N}-1$ between control $(0.62 \pm 0.10 \mathrm{~m}$ and $0.63 \pm 0.16$ $\mathrm{m}$, respectively) and slow $(0.49 \pm 0.15 \mathrm{~m}$ and $0.56 \pm 0.12 \mathrm{~m}$, respectively) conditions $\left(\mathrm{F}_{3,88}=6.18, p<.01 ; \mathrm{F}_{3,88}=3.41, p<.05\right.$, respectively); and between fast $\left(0.63 \pm 0.13 \mathrm{~m}\right.$ and $0.66 \pm 0.14 \mathrm{~m}$, respectively) and slow speeds $\left(\mathrm{F}_{3,88}=6.40, p<\right.$ $.01 ; \mathrm{F}_{3,88}=4.47, p<.01$, respectively; Figure $2 \mathrm{~b}$ ). In the intracondition comparison for the step length during the approach phase (Figure $2 b$ ), the N-1 was bigger than the $\mathrm{N}-2$ at fast speed $\left(\mathrm{t}_{49}=-2.68, p<.01\right)$ and slow speed $\left(\mathrm{t}_{49}=-4.88, p<.001\right)$. 


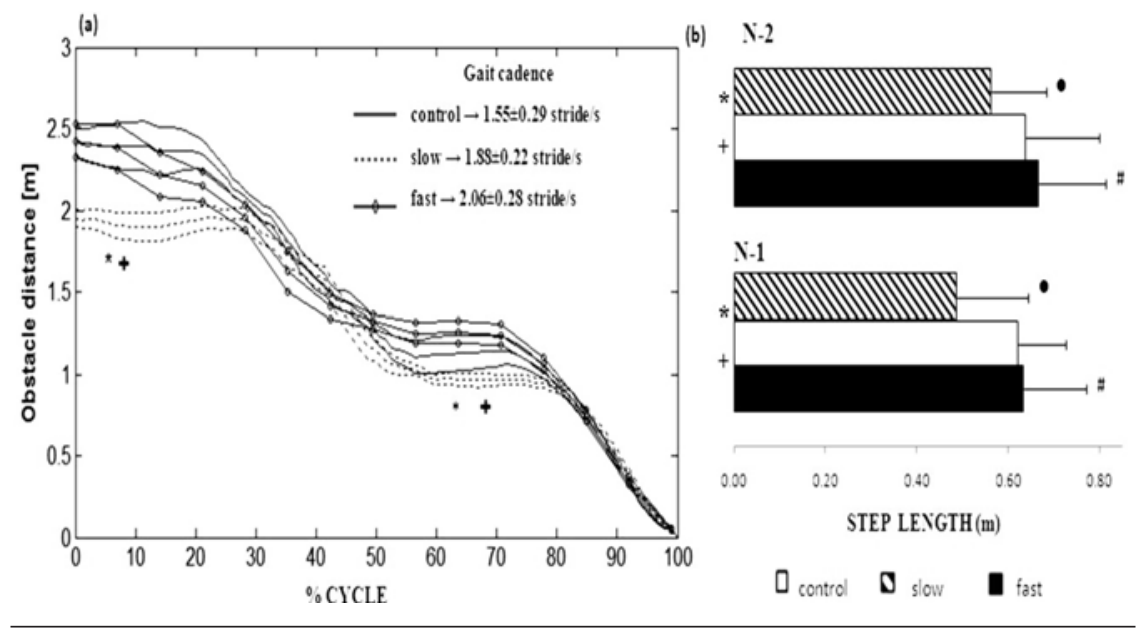

Figure 2 - (a) Median and confidence interval of the horizontal linear distance to the obstacle with the respective gait cadence mean and standard deviation values. The cycle corresponded to N-2 (0\%) until right calcaneus above the obstacle (100\%). (b) Mean and standard deviation values of the $\mathrm{N}-2$ and $\mathrm{N}-1$. * - control condition $\neq$ slow speed condition, + - slow speed condition $\neq$ fast speed condition, $\bullet-\mathrm{N}-2 \neq \mathrm{N}-1$ in the slow speed condition; $\#-\mathrm{N}-2 \neq \mathrm{N}-1$ in fast speed condition.

The analysis of the horizontal linear distance to the obstacle during N-1 showed a shorter distance between the participants and the obstacle at slow speed. The differences occurred in gait cycle intervals: $0-35 \%$ and $65-77 \%$ in relation to the control condition; $0-21 \%$ and $60-80 \%$ in relation to the fast speed condition (Figure 2a).

ANOVA showed the effect of the obstacle speed on the safety margin, represented by toe clearance, and the horizontal foot-obstacle distances before crossing and the obstacle-foot distance after crossing (Figure 3). ANOVA showed a larger safety margin in the fast $(0.18 \pm 0.05 \mathrm{~m})$ speed condition in comparison with the control $(0.17 \pm 0.03 \mathrm{~m})$ condition $\left(\mathrm{F}_{3,88}=3.57, p<.05\right)$ and shorter take-off distance in the slow $(0.18 \pm 0.04 \mathrm{~m})$ speed condition in relation to the control $\left(\mathrm{F}_{3,88}=5.70\right.$, $p<.01)$ and fast speed $\left(\mathrm{F}_{3,88}=6.52, p<.01\right)$ conditions. For the landing distance, the control $(0.37 \pm 0.03 \mathrm{~m})$ condition distance was significantly shorter than that of the slow $(0.43 \pm 0.04 \mathrm{~m})$ speed condition $\left(\mathrm{F}_{3,88}=8.72, p<.01\right)$, which was shorter than that of the fast $(0.46 \pm 0.07 \mathrm{~m})$ speed condition $\left(\mathrm{F}_{3,88}=5.98, p<.01\right)$.

ANOVA of the absolute error (Figure 4a) indicated a significantly smaller error for the fast $(0.11 \pm 0.09 \mathrm{~m})$ speed condition relative to the control $(0.16 \pm 0.07 \mathrm{~m})$ condition $\left(\mathrm{F}_{3,88}=4.03, p<.05\right)$. For temporal variables before and during obstacle crossing, the analysis of the speed conditions revealed a significant difference in the duration of the N-2 before the obstacle approach (Figure 4b) between the three conditions. The longest duration was measured for the slow $(0.30 \pm 0.04 \mathrm{~s})$ speed condition, and the shortest duration, for the fast $(0.23 \pm 0.03 \mathrm{~s})$ speed condition with the control $(0.27 \pm 0.03 \mathrm{~s})$ condition in between of them (control and slow speed conditions $-\mathrm{F}_{3,76}=6.43, p<.01$; and control and fast speed conditions $-\mathrm{F}_{3,76}=$ $7.14, p<.01$; and slow and fast speed conditions $\left.-\mathrm{F}_{3,76}=13.57, p<.01\right)$. The N-1 


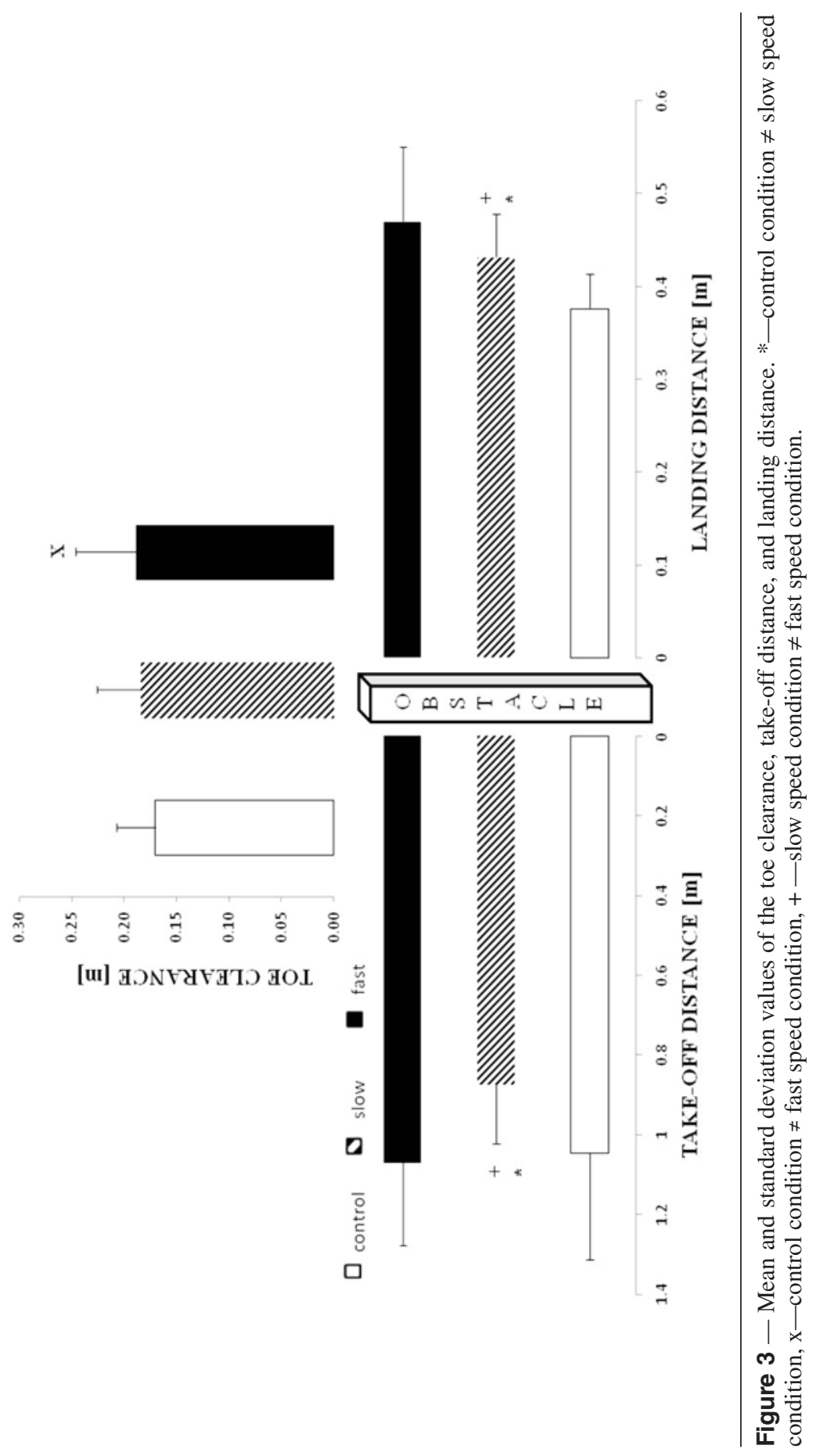




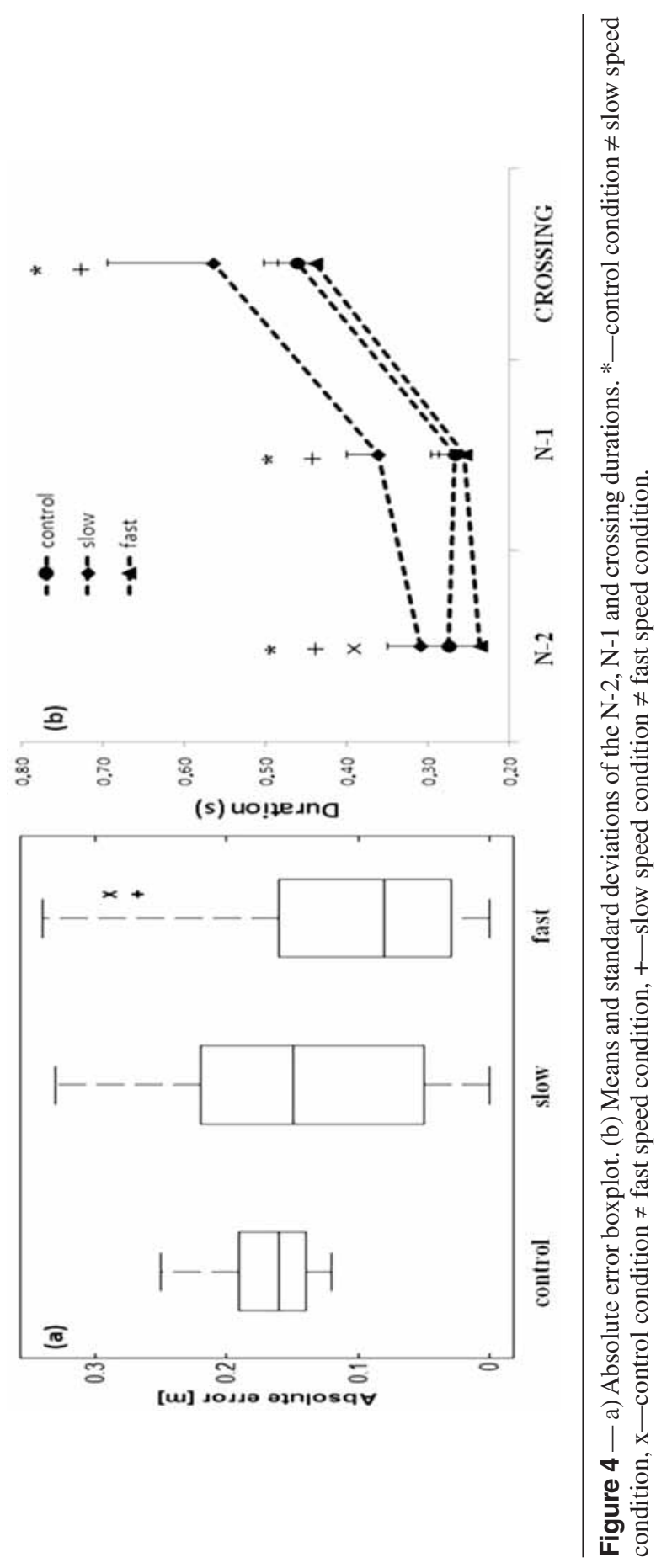


and crossing durations (Figure 4b) were significantly longer for the slow (0.36 \pm $0.03 \mathrm{~s})$ speed condition when compared with the control $(0.26 \pm 0.03 \mathrm{~s})$ condition $\left(\mathrm{F}_{3,88}=6.90, p<.01 ; \mathrm{F}_{3,88}=7.05, p<.01\right.$, respectively $)$ and the fast $(0.25 \pm 0.03 \mathrm{~s})$ speed condition $\left(\mathrm{F}_{3,88}=7.76, p<.01 ; \mathrm{F}_{3,88}=8.54, p<.01\right.$, respectively $)$.

The fast $(2.62 \pm 0.34 \mathrm{~m} / \mathrm{s})$ speed condition $\left(\mathrm{F}_{3,88}=84.61, p<.001\right)$ showed an average speed significantly higher than that of the control $(2.30 \pm 0.49 \mathrm{~m} / \mathrm{s})$ condition, which, in turn, was significantly higher than that of the slow (1.58 \pm $0.33 \mathrm{~m} / \mathrm{s}$ ) speed condition (Figure 5a). When analyzing the gait linear speed in the N-1 (Figure 5a), the slow speed condition showed a significantly slower gait speed
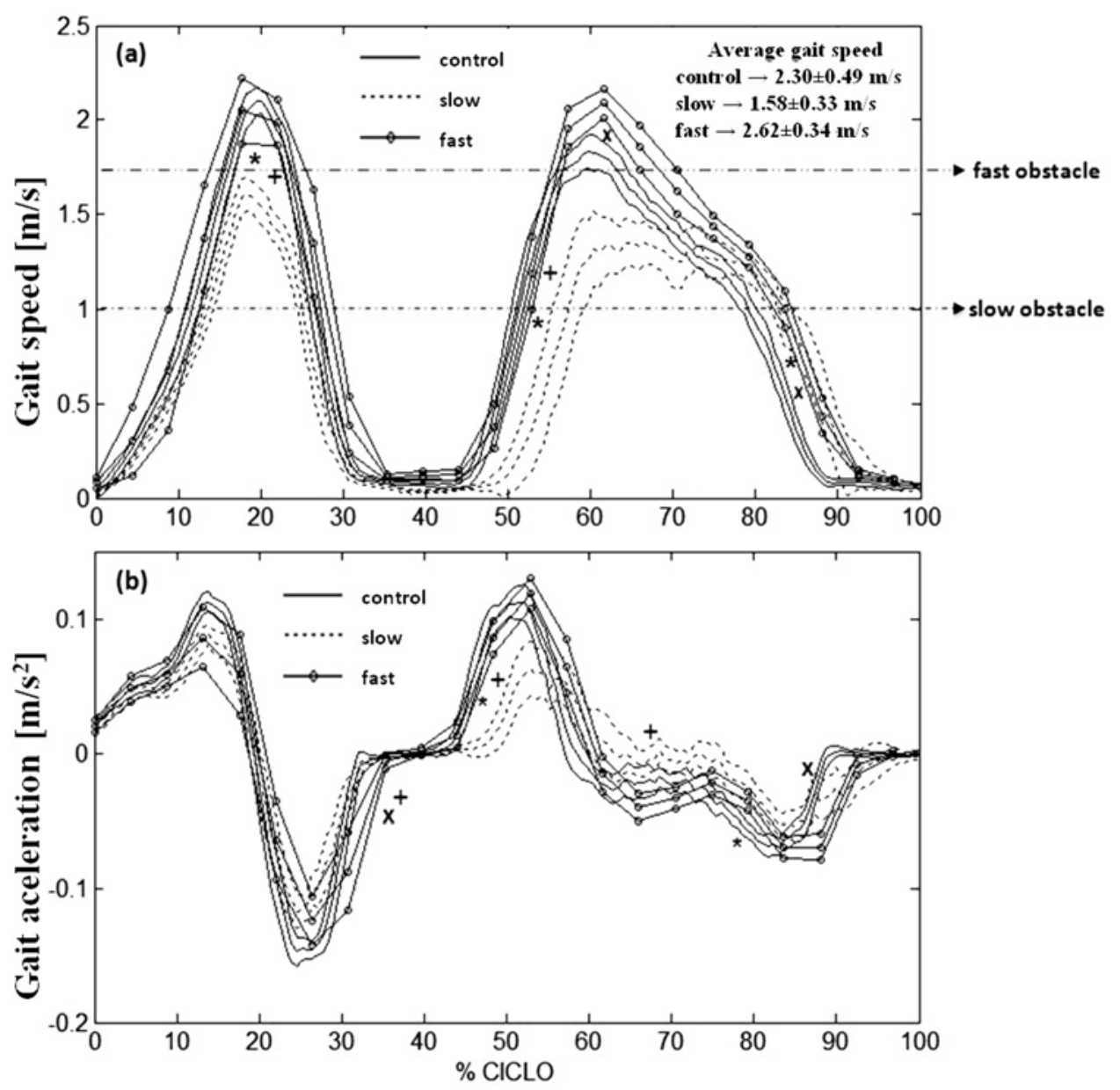

Figure 5 - Median and confidence interval of the linear gait speed and average gait speed. *-control condition $\neq$ slow speed condition, $x-$ control condition $\neq$ fast speed condition, + - slow speed condition $\neq$ fast speed condition. 
in certain parts of the cycle in comparison with the control condition (11-17\%, $24-29 \%, 44-53 \%$, and 79-83\% of the cycle) and the fast speed condition (31-36\%, $44-54 \%$, and $66-74 \%$ of the cycle). The linear gait speed in the fast speed condition was significantly higher than that in the control condition from 58 to $92 \%$ of the cycle. It is also noticeable that in the $\mathrm{N}-1$ of the slow speed condition, the gait speed remained in the $60-80 \%$ range of the gait cycle.

The analysis of the confidence interval of gait linear acceleration revealed a difference between: a) slow speed and control conditions in the 44-53\% and 79-83\% intervals of the cycle; b) fast speed and control conditions in the $31-36 \%$ and $88-92 \%$ intervals; c) fast and slow speed conditions in the intervals 31-36\%, $44-54 \%$, and $66-74 \%$ of the cycle (Figure $5 \mathrm{~b}$ ). It is also noticeable a delay in the $\mathrm{N}-1$ acceleration in the slow speed condition around $43 \%$ and maintenance of acceleration from $63 \%$ to $77 \%$ of the cycle.

\section{Discussion}

This study is innovative, since there are no reports in the literature on adaptive locomotion in crossing a perpendicularly moving obstacle. Our results confirmed the study hypothesis: obstacle speed affects gait parameters with the space-time adjustments distinct for the speed conditions studied. However, the slow speed condition showed a higher number of locomotion changes than the other conditions did and adjustments were differently controlled in each condition.

Locomotion in complex environments (moving objects, people, animals, different surfaces, etc.) requires adaptive ability from the locomotor system to avoid and cross uneven grounds (Krell \& Patla, 2002), devoting more attention (Bradshaw $\&$ Sparrow, 2001), especially when crossing an obstacle (Patla et al., 1996). Slow moving objects allow larger exploration and collection of relevant information as a consequence of increased time of vision for planning the action (Tresilian, 2004), anticipating the magnitude of the perturbation. The decreased step length (GérinLajoie, Richards \& McFadyen, 2005), gait speed and cadence, and the increased duration of the N-2 and N-1 found in this study disclose the participation of the proactive mechanisms for modulation of the effector system according to the perceived environmental characteristics. The modulation happened during crossing the obstacle unveiling the anticipatory strategy to guarantee dynamic stability (Patla, 2003). The decreased take-off distance, the increased landing distance, and the increased crossing duration allowed safely crossing with anticipatory strategies, similarly to the posture-preserving strategy (Harley, Wilkie \& Wannc, 2009).

The adjustments used in the approach and crossing phases are influenced by the sensory information. In the approach phase, visual information about the obstacle features can modulate the effector system by the corticospinal pathways (Dietz, 2003), including the upper motor neurons originating in the premotor cortex, which are involved in select movements appropriate to the context of the action and to the individual intention (Purves et al., 2004). During the crossing phase of a mobile obstacle, the central nervous system must solve two related problems: to control the body posture and orientation and to modulate precisely the lower limbs according to spatial and temporal task constraints. To accomplish these problems, the central nervous system uses the direct and indirect routes to modulate the 
activity of the spinal pattern generators (Dietz, 2003). For controlling the body posture and orientation, the adjustments may also have been influenced by the upper motor neurons originating in the brainstem, including the vestibulospinal and the reticulospinal tracts (Dietz, Trippel \& Hortzmann, 1991; Purves et al., 2004). The reticular formation neurons and the upper motor neurons in the motor cortex have been regarded in the production of both precise and smooth movements involving appropriate degree of muscle contraction to perform the task (Duysens \& Van De Crommert, 1998; Gordon, 1991), such as the toe clearance.

Proprioceptive and exproprioceptive information controlled the anticipatory modulation at crossing the obstacle in the slow speed condition. The use of exteroceptive information in an anticipation mode to plan the action in advance (Gérin-Lajoie, Richards \& McFadyen, 2005) explains the behavior in the approach phase. These results confirm the existence of three phases in the approach pattern: acceleration, global visual control, and local visual control (Bradshaw \& Sparrow, 2001), included in the proactive control mechanism.

The global and local visual control phases in the obstacle approach are clear in the analysis of the linear gait speed in N-1 (60-90\% of the cycle). The speed maintenance was a way of engaging the effector system to the task objective. Maintaining a constant speed for a certain period indicates that the effector system is forward in relation of the obstacle in the slow speed condition. The decreased length and increased duration of the last two steps (N-2 and N-1) and particularly the participant's anticipation of the obstacle (Figure 2a) confirmed this pattern. Waiting for the obstacle also triggered anticipatory adjustments, such as N-1 longer than the $\mathrm{N}-2$ decreased take-off distance, and increased landing distance. In addition, the delay and decreased linear acceleration in the $\mathrm{N}-1$ ( $43 \%$ of the cycle) were compensated by the increased duration of the $\mathrm{N}-1$ and decreased gait speed. Action planning through proactive control mechanism seems to indicate that the participants prioritize efficiency (performance) rather than economy (caloric spent) (Patla, 2003) in the approach phase in the slow speed condition.

In contrast for slow speed condition, the fast speed shows shorter interaction time of the sensory and motor systems. This was indicated in the decreased N-2 duration. Therefore, the participants tried to predict the crossing moment. The time available for the participants to use vision for an anticipatory strategy when crossing the obstacle was reduced as the initial path and acceleration of the obstacle was blocked from subject view. Therefore, past experience was more important to predict the motor perturbation. It is clear that a little of anticipatory strategy could have been used when crossing the obstacle since it was primarily predictive. The increase in the $\mathrm{N}-1$ length in relation to that of the $\mathrm{N}-2$ and in the linear speed of the $\mathrm{N}-1$ in the fast speed condition shows that the locomotor changes in the approach phase were feedforward planned (Rosenbaum, 1991; Shumway-Cook \& Woollacott, 1995) or late planned (Gérin-Lajoie, Richards \& McFadyen, 2005). To correct the late plan crossing the obstacle in the fast speed conditions some adjustments are necessary. These adjustments happened as a predictive strategy and helped by the integration of vestibular, visual, somato-sensory, and motor systems information (Kandell, 1991; Horak \& Macpherson, 1996), resulted in an appropriate coupling for crossing the obstacle more closely to the obstacle midpoint. Coupling occurred after 58\% of the cycle (Figure 5a), when the linear speed in the fast speed condition was higher than that of the control and in slow speed conditions, which cor- 
roborates with a previous report on the need of movement acceleration to meet the task requirement (Lenoir et al., 2002). The coupling, the decreased absolute error and increased margin of safety and take-off distance in the fast speed condition indicate a proactive strategy (Patla, 2003).

During obstacle crossing, the individual may experience errors such as stopping in front of the obstacle or going around the obstacle which are caused by sensory and motor factors. Visual system plays a crucial role in the action planning (Gérin-Lajoie, Richards \& McFadyen, 2005; Patla, 2003; Patla, Cinelli \& Greig, 2006). The association of the sensory and the effector systems is important for accomplishing the task effectively (Patla, 1991; Patla et al., 1996; Krell \& Patla, 2002; Mohagheghi, Moraes \& Patla, 2004). Complex tasks disturb the sensory and motor system coupling, reducing the chances of success in the task and involving increased mental processing (Gérin-Lajoie, Richards \& McFadyen, 2005). This fact was evidenced in this study when the percentage of repeated trials was analyzed, which was higher $(20 \%)$ than the $0.5 \%$ level evidenced by other studies (Patla, Prentice \& Gobbi, 1996; Chen et al., 1991). Two factors may have influenced this result, the obstacle height and motion (Mohagheghi, Moraes \& Patla, 2004). The obstacle height $(41.5-51.5 \mathrm{~cm})$ customized to each participant was higher than usual $(\approx 27 \mathrm{~cm})$. A higher obstacle demanded more from the motor control system, requiring appropriate obstacle approaching and crossing adjustments from the effector system. Regarding the obstacle motion, it made the synchronization of the participants' movement with the obstacle movement difficult. The determination of the obstacle location for its interception depends on the time available for its viewing (Tresilian, 2004). In the fast speed condition, the interceptive action seems to be little guided by sensory information during the approach phase, more dependent on preprogramming (predictive strategy), and more precise. In contrast, in the slow speed condition, sensory information is more used in adjusting spatial and temporal variables in the approach phase (anticipatory strategy), although less precisely. The slow speed condition demanded more space-time adjustments and may be considered more difficult to be performed. Crossing a slow moving obstacle resulted in more adjustments than in the fast speed condition. Perhaps $1.71 \mathrm{~m} / \mathrm{s}$ was not fast enough to afford the expected locomotor adjustments. The locomotor adjustments observed in each speed condition confirm the attempt to reduce the complexity of the proposed task (Cinelli, Patla \& Allard, 2008).

While our results are important, this study was not without its limitations. The track on targeting can influence the perception of the participant, disturbing kinematic variables. However, during our day we have similar situations that causing changes in our insight and in the locomotion. The board placed at the beginning of the obstacle path which prevented the subject's perception of the obstacle acceleration can make it difficult to determine predictive and anticipatory strategy. The use of only the right (dominant) limb to cross the obstacle was a limitation of the method. It would be interesting to examine the left limb as the lead limb crossing the obstacle.

\section{General Conclusions}

Contrary to the expectations, the slow speed obstacle-crossing condition resulted in more locomotor adjustments than in the fast speed condition. The studied conditions 
presented differences in strategies and adjustments. The fast speed condition was dependent on preprogramming, mainly by the feedfoward or in the late planning stage mechanisms, showing a predictive strategy during the approach phase and during the obstacle crossing. The priority in this condition was to increase the safety margin. In the slow speed condition, the sensory information was largely used and indicated anticipatory adjustments during the movement. During the performance of the slow condition, anticipation regarding the obstacle movement was used, being necessary to wait for the obstacle for the system coupling and attaining the goal. It showed an anticipatory strategy in both the approach and the crossing phases.

\section{References}

Abdel-Aziz, Y.I., \& Karara, H.M. (1971). Direct linear transformation from comparator coordinates into object space coordinates in close-range photogrammetry. Proceedings of the ASP/UI Symposium on Close-Range Photogrammetry, pp. 1-18. Falls Church, VA: American Society of Photogrammerty.

Bradshaw, E.J., \& Sparrow, W.A. (2001). Effects of approach velocity and foot-target characteristics on the visual regulation of step length. Human Movement Science, 20, 401-426.

Chen, H.C., Ashton-Miller, J.A., Alexander, N.B., \& Schultz, A.B. (1991). Stepping over obstacles: gait patterns of healthy young and old adults. Journal of Gerontology, 46, M196-M203.

Cinelli, M.E., Patla, A.E., \& Allard, F. (2008). Strategies used to walk through a moving aperture. Gait \& Posture, 27, 595-602.

Dietz, V. (2003). Spinal cord pattern generators for locomotion. Clinical Neurophysiology, 114, 1379-1389.

Dietz, V., Trippel, M., \& Hortzmann, G.A. (1991). Significance of proprioceptive and vestibule-spinal reflexes in the control of stance and gait. In A.E. Patla (Ed.), Adaptability of Human Gait (pp. 37-52). Amsterdam: Elsevier.

Duysens, J., \& Van de Crommert, H.W.A.A. (1998). Neural control of locomotion, Part 1: the central pattern generator from cats to humans. Gait \& Posture, 7, 131-141.

Figueroa, P.J., Leite, N.J., \& Barros, R.M.L. (2003). A flexible Software for tracking of markers used in Human Motion Analysis. Computer Methods and Programs in Biomedicine, 72, 155-165.

Gérin-Lajoie, M., Richards, C.L., \& McFadyen, B.J. (2005). The negotiation of stationary and moving obstructions during walking: anticipatory locomotor adaptations and preservation of personal space. Motor Control, 9, 242-269.

Gérin-Lajoie, M., Richards, C.L., \& McFadyen, B.J. (2006). The circumvention of obstacles during walking in different environmental contexts: A comparison between older and younger adults. Gait \& Posture, 24, 364-369.

Gordon, J. (1991) Spinal mechanisms of motor coordination. In Kandel, E.R., Schwartz, J.H., \& Jessell, T.M. (Eds). Principles of Neural Science. 3 ed. Norwalk, Appleton \& Lange, pp.581-595.

Harley, C., Wilkie, R.M., \& Wannc, J.P. (2009). Stepping over obstacles: Attention demands and aging. Gait \& Posture, 29, 428-432.

Horak, F.B., \& Macpherson, J.M. (1996). Postural orientation and equilibrium. In: Rowell, L.B., Shepherd, J.T. (Eds). Handbook of Physiology Section 12: Exercise: Regulation and Integration of Multiple Systems. New York: Oxford University Press, pp.255-292.

Kandell, E.R. (1991). Perception of motion, depth, and form. In Kandell, E.R., Schwartz, J.H., Jessell, T.M. (Eds) Principles of Neural Science. 3 ed. Norwalk: Appleton \& Lange, pp. 440-466. 
Krell, J., \& Patla, A.E. (2002). The influence of multiples obstacles in the travel path on avoidance strategy. Gait \& Posture, 16, 15-19.

Lenoir, M., Musch, E., Thiery, E., \& Salversbergh, G.J.P. (2002). Rate of change of angular bearing as the relevant property in a horizontal interception task during locomotion. Journal of Motor Behavior, 34, 385-401.

Lindenberger, U., Marsiske, M., \& Baltes, P.B. (2000). Memorizing while walking: increase in dual-task costs from young adulthood to old age. Psychology and Aging, 5, 417-436.

Loomis, J.M., \& Beall, A.C. (1998). Visually controlled locomotion: its dependence on optic flow, 3D space perception and cognition. Ecological Psychology, 10, 271-285.

MacGill, R., Tukey, J.W., \& Larsen, W.A. (1978). Variations of box plots. The American Statistician, 32, 12-16.

Mohagheghi, A.A., Moraes, R., \& Patla, A.E. (2004). The effects of distant and on-line visual information on the control of approach phase and step over an obstacle during locomotion. Experimental Brain Research, 155, 459-468.

Patla, A.E. (1991). Understanding the control of human locomotion: a prologue. In A.E. Patla (Ed.), Adaptability of Human Gait (pp. 13-17). Amsterdam: Elsevier.

Patla, A.E. (1997). Understanding the roles of vision in the control of human locomotion. Gait \& Posture, 5, 54-69.

Patla, A.E. (2003). Strategies for dynamic stability during adaptive human locomotion. IEEE Engineering in Medicine and Biology Magazine, 22, 48-52.

Patla, A.E., Cinelli, M., \& Greig, M. (2006). Coupling environment information from visual system to changes in locomotion patterns: Implications for the design of adaptable biped robots. In H. Kimura, K. Tsuchiya, A. Ishiguro, \& H. Witte (Eds.), Adaptive Motion of Animals and Machines (pp. 281-298). Tokyo: Springer.

Patla, A.E., Prentice, S.D., \& Gobbi, L.T.B. (1996). Visual control of obstacle avoidance during locomotion: strategies in young children, young and older adults. In A.M. Ferrandez \& N. Teasdale (Eds.), Changes in Sensory Motor Behavior in Aging (pp. 257-275). Amsterdam: Elsevier Science.

Patla, A.E., Rietdyk, S., Martin, C., \& Prentice, S. (1996). Locomotor patterns of the leading and the trailing limbs as solid and fragile obstacles are stepped over: some insights into the role of vision during locomotion. Journal of Motor Behavior, 28, 35-47.

Purves, D., Augustine, G.J., Fitzpatrick, D., Hall, W.C., Lamantia, A-S., Mcnamara, J.O., et al. (Eds.). (2004). Neuroscience. 3 ed. Sunderland, Massachusetts: Sinauer Publishers.

Rosenbaum, D.A. (1991). Human Motor Control. San Diego: Academic Press.

Shumway-Cook, A., \& Woollacott, M.H. (1995). Motor Control: Theory and Practical Applications. Maryland: Williams \& Wilkins.

Siu, K.C., Catena, R.D., Chou, L.S., Van Donkelaar, P., \& Woollacott, M.H. (2008). Effects of a secondary task on obstacle avoidance in healthy young adults. Experimental Brain Research, 184, 115-120.

Tresilian, J.R. (2004). The accuracy of interceptive action in time and space. Exercise and Sport Sciences Reviews, 32, 167-173.

Troisi, A. (2005). The concept of alternative strategies and its relevance to psychiatry and clinical psychology. Neuroscience and Biobehavioral Reviews, 29, 159-168.

Watanabe, K. (2004). Visual grouping by motion precedes the relative localization between moving and flashed stimuli. Journal of Experimental Psychology, 30, 504-512.

Winter, D.A. (1991). The Biomechanics and Motor Control of Human Gait. 2 ed. Waterloo: University of Waterloo. 
Copyright of Motor Control is the property of Human Kinetics Publishers, Inc. and its content may not be copied or emailed to multiple sites or posted to a listserv without the copyright holder's express written permission. However, users may print, download, or email articles for individual use. 